\title{
Persistence of Policy Shocks to the Ecological Footprint of MINT Countries
}

\author{
Ali Eren ALPER ${ }^{1} \odot$, F. Özlem ALPER ${ }^{2} \odot$
}

\begin{abstract}
The main purpose of this study is to test the stability of the ecological footprint and its sub-components in Mexico, Indonesia, Nigeria, and Turkey (MINT) by performing the Fourier unit root test, which yields reliable results in the presence of an unknown number and form of breaks, on the data obtained over the period 1961-2016. Unit root tests provide information regarding future behaviors based on the previous data of the series. In this respect, suggestions for policymakers can be made by determining that shocks have either permanent or temporary impacts on the series. As a result of the analysis, since the cropland footprint for Mexico; the total ecological footprint and construction area footprint subcomponent for Indonesia; cropland and grazing land footprint subcomponents for Nigeria; and the fishery and forestry subcomponents for Turkey are detected as stationary, it is concluded that policies to reduce the level of pollution are ineffective for these components. Moreover, it was detected that the carbon footprint subcomponent is not stationary in all the MINT countries, and policies to reduce carbon emissions would have permanent impacts.
\end{abstract}

Keywords: Ecological footprint, Fourier unit root, MINT countries, Stationarity, Global warming

JEL Codes: C22, Q57, Q58

\section{Introduction}

The full circumstance of the environment, as one of the basic elements determining people's quality of life, has now become one of the leading domains of interest on a global scale. As of today, environmental pollution poses an enormous threat for both developed and developing countries. Previously, the measurement of quality of life had been determined merely in terms of physical output growth until the dawn of the $21^{\text {st }}$ century. However, there is an overall consensus that the degradation in environmental quality renders the sustainability of economic growth impossible and poses a major obstacle to the prevention of poverty (Munasinghe, 1992).

The decline in the size and quality of natural resource capacity restricts the livelihood of the existing population as well as that of future generations. Humanity transforms natural resources to boost the production of goods and services and to ensure the sustainability of its supply. Production of goods and services requires not only natural resources but also labor force. Nonetheless, the labor force cannot subsist without natural resources. Therefore, natural resources are required for the continuity of both the labor force and the production of goods and services (Tisdell, 2010).

In environmental economics literature, $\mathrm{CO}_{2}$ is used as an environmental pollution criterion due to the availability of a large dataset and its contribution to creating greenhouse gases. A few studies also used other ecological indexes such as a sulfur dioxide and hanging particulate matter instead of $\mathrm{CO}_{2}$ emissions (Ozturk et al., 2016). However, it is not rational to consider merely a single indicator (or type of contamination) for examining environmental pollution. Thus, Rees (1992) and Wackernagel (1994) designed a measurement named ecological footprint (EF). This measurement method takes various standards of degradation such as soil, forests, and mines into account (Ulucak \& Lin, 2017). EF consists of six components, namely, croplands, 
grazing lands, forest lands, fishing grounds, built-up lands, and carbon footprint. Since EF concentrates on many resource reserves, policy implications based on this measurement are also more efficient than those made in accordance with a single pollution indicator.

Upon calculating the $E F$, the global footprint network keeps track of the extent to which people need biologically efficient areas to fulfill their competing demands. These demands include areas for food production, the absorption of the $\mathrm{CO}_{2}$ emissions stemming from fossil fuel burning, and the construction of the necessary infrastructures. The ecological consumption of a country is determined by adding imports to its national production and subtracting exports. Biologically productive lands and seas are required in order to produce all goods and to accommodate the waste stemming from their production. Therefore, international trade can actually be perceived as the flow of embedded EF, which uses primary yields from croplan$\mathrm{ds}$, forests, grazing lands, and fisheries to calculate the amount of whatever is required to support a particular activity. Biological capacity is measured by calculating the amount of biologically efficient land and sea areas available to provide resources consumed by a population and absorb generated wastes, given current technology and management practices. To ensure that biological capacity is comparable over time, areas are adjusted in proportion to their biological productivity. These adjusted areas are referred to as global hectares (gha) ("Global Footprint Network," 2018).

$$
E F_{C}=E F_{P}+\left(E F_{I}+E F_{E}\right)
$$

Equation 1 is used for calculating the EF. Accordingly, $E F_{C}$ denotes the EF of consumption, which indicates the consumption of bio capacity by a country's residents. $E F_{P}$ denotes the footprint of production and indicates the consumption of bio capacity stemming from production processes within a given geographic area, such as a country or society. The variables $E F_{I}$ and $E F_{E}$ denote the EFs of imports and exports, respectively. The net EF of international trade is determined by subtracting the EF of exports from the EF of imports. If the country's embedded $E F$ in exports is higher than that of imports, the country is a net exporter of renewable resources and ecological services. The ecological impacts of countries are determined at the end of this calculation. Countries have ecological reserves when the footprint of the country exceeds its biological capacity ("Global Footprint Network," 2018).
MINT countries consisting of Mexico, Indonesia, Nigeria, and Turkey were selected for the analysis in this study within the range of the 1961-2016 period. Several important reasons validate the selection of these countries, the time range, and the dataset. The first one involves, as also stated in Solarin and Bello (2018), the convenience of categorizing the countries in accordance with their economic properties rather than their geographic locations while examining the unit root features of EF. Developing economies are, in general, middle-income countries with the same economic features. Many developing countries are industrial economies. In other words, the transformation of their economies to the service economy is not yet complete. The second reason involves, as stated in Stern (2004), the fact that the amount of polluter per output lessens depending on the technological improvements and environmental regulations in both industrialized and emerging countries, although the amount of per capita waste and the level of pollution increase. For this reason, it is appropriate to use EF as the environmental degradation proxy variable in order to determine the unit root characteristics of the countries' overall pollution levels. Third, the reliability of the data in both developed and developing countries is higher since the reliability of the institutions that collect information in such countries is higher than of the less developed countries.

This study contributes to the literature in terms of two aspects. The first aspect involves the fact that the KPSS unit root test developed by Kwiatkowski et al. (1992) and extended by the Fourier function (FKPSS) is used in the study. The FKPSS test would be able to detect both smooth and sharp breaks in the EF series. The second important contribution of the study to the literature involves the fact that only a few studies directly examined the unit root properties of EF in emerging economies. Thus, common policy implications can also be made for these countries with identical economic features.

The main objective of this study is to test the unit root properties of EF and its components for the MINT countries over the period 1961-2016 via the FKPSS unit root test, which allows both smooth and sharp structural breaks. The remaining sections of the study are as follows: The second section presents the empirical literature. The third section presents the data and the methodology used in this study, while the fourth section reports the empirical findings obtained 
from the study. The fifth section considers some policy implications and conclusions.

\section{Empirical Literature}

To our knowledge, only a few studies in the literature directly tested the unit root properties of EF. Ulucak and Lin (2017) aimed at identifying the stochastic behaviors of EF in the USA during the period 1961-2013 and determining its reactions to policy shocks. In the analysis performed with the Fourier unit root test, it was determined that EF had a non-stationary structure. Solarin and Bello (2018) examined the unit root characteristics of EF by courtesy of the nonlinear unit root test developed by Kruse (2011) and the linear unit root test developed by Narayan and Popp (2010) in a sample group of 128 countries. The study found that the series were non-stationary and contained unit roots in 96 countries ( $81 \%$ of the sample); hence, they did not have mean-reverting tendency. Ozcan et al. (2019) investigated whether or not environmental policies were effective for various income groups in countries classified by World Bank income groups during the period 1961-2013 using the panel unit root test developed by Kapetanios et al. (2003). The EF of all high-income group countries and half of the low- and middle-income countries were detected to be stationary. Solarin et al. (2019) tested the stationarity of the carbon footprint, which was considered as a criterion for environmental degradation in 92 countries during the period 1961-2014 using the frictional unit root test. The analysis results determined that the series in 25 countries had mean-reverting tendency.

Several studies in the literature conducted stationarity analysis. The most commonly used environmental degradation criterion is the level of carbon emissions. There are a few important motivations for conducting a unit root analysis of carbon emissions in the literature. The initial reason is that if the unit root is detected in the carbon emission series, a policy shock applied to these ecological indicators would have a permanent impact. Second, the non-stationary carbon emission series would have important implications for the environmental Kuznets curve (EKC) hypothesis in the long-term. Third, examining the stationarity properties of carbon emissions would enable people to obtain information about the effectiveness of the convergence concept (Solarin \& Bello, 2018). Aldy (2006) examined the convergence of per capita $\mathrm{CO}_{2}$ emissions for the Organisation for Economic Cooperation and Development (OECD) countries throughout the period of 1960-2000. Convergence was detected in 23 OECD member countries, whereas divergence was detected in 88 countries worldwide. Camarero et al. (2013) analyzed the stationarity of emission intensity during the period 1960-2008 by courtesy of Phillips and Sul's (2007) methodology. The analysis results revealed that the emission intensities converged. Christidou et al. (2013) investigated the stationarity of $\mathrm{CO}_{2}$ emissions in 36 countries during the period $1870-2006$ by panel unit root test. According to the analysis results, it was determined that the series were stationary; hence, they converged. Li and Lin (2013) analyzed the stationarity of per capita $\mathrm{CO}_{2}$ emissions in a sample group of 110 countries during the period 1971-2008 and detected very few findings for convergence, whereas they detected convergence of sub-samples according to income groups. Li et al. (2014) analyzed the stationarity of $\mathrm{CO}_{2}$ emissions in 50 states of the USA using the sequential panel selection method during the period 1990-2010. It was determined that $\mathrm{CO}_{2}$ emissions converged in 12 out of 50 states, whereas they diverged in the other 38 states. Barros et al. (2016) analyzed the stationarity characteristics of global $\mathrm{CO}_{2}$ emissions, their components, and per capita $\mathrm{CO}_{2}$ emissions. In the analysis using the frictional unit root test, the order of integration of all series was determined as above one. Ahmed et al. (2017) analyzed the convergence of per capita $\mathrm{CO}_{2}$ emissions in 162 OECD and non-OECD countries with high and low-income levels, using the data obtained during the period 1960-2010 via wavelet-based unit root test. The analysis results suggest that convergence occurred in 18 high-income OECD, 2 high-income non-OECD, 13 middle-income, and 5 low-income countries, whereas divergence occurred in the remaining 124 countries. Presno et al. (2018) examined the convergence of per capita $\mathrm{CO}_{2}$ emissions in $28 \mathrm{OECD}$ member countries during the period 1901-2009. The study was conducted at two aggregation levels: the first for all countries and the second for both developing and developed countries. Stochastic convergence was detected in the first-level analysis, whereas certain dispersions in terms of $\beta$-convergence were detected in the second-level analysis, especially for developed countries. Shahbaz et al. (2019) analyzed the unit root properties of per capita $\mathrm{CO}_{2}$ emissions in 98 countries between 1975-2014. In the study using the nonlinear unit root test developed by Kruse (2011), it was determined that the series were non-stationary in most of the countries included in the analysis, whereas in only nine countries the series were stationary. 
The second field of examination in the empirical literature involves testing the EKC hypothesis. Zambrano-Monserrate et al. (2018) tested the EKC hypothesis using per capita $\mathrm{CO}_{2}$ emission data obtained during the period 1980-2011 in Peru. In the study using the ARDL method, the EKC hypothesis was found to be invalid for Peru. Destek and Sarkodie (2019) examined the EKC hypothesis in 11 new industrialized countries using the EF variable during the period 1977-2013 via the panel data analysis method. Analysis results detected the existence of an inverted U-shaped relationship between EF and economic growth. Hove and Tursoy (2019) examined the EKC hypothesis using the panel generalized method of moments within the data range of 2000-2017 in 24 developing countries. The analysis results suggested that per capita $\mathrm{CO}_{2}$ emission decreases as the gross domestic product increases; however, the nitrogen oxide $\left(\mathrm{NO}_{x}\right)$ emission increases. Chen and Taylor (2020) examined the EKC hypothesis using the emissions of heavy metals as a proxy of environmental quality for Singapore within the data range of 19002017 and found it to be valid in Singapore. Bekhet et al. (2020) analyzed the EKC hypothesis for Malaysia within the data range of 1971-2013, using $\mathrm{CO}_{2}$ emissions. Analysis results indicated that the hypothesis was valid.

The third and last application area in the environmental economics literature is the pollution haven hypothesis (PHH). Sun et al. (2017) analyzed PHH using the annual data obtained from China during the period 1980-2012 using the ARDL method. Analysis results indicated that $\mathrm{PHH}$ was valid in China. Solarin et al. (2017) examined the validity of PHH during the period 1980-2012 for Ghana using the ARDL method. Analysis results indicated that $\mathrm{PHH}$ was valid in Ghana. By courtesy of multinational input-output tables, Cai et al. (2018) investigated whether or not developing countries were pollution havens for developed economies. The results indicated that China was the pollution haven for 22 developed countries, whereas 19 developing countries were pollution havens for China. López et al. (2018) tested the validity of PHH within the data range of 1995-2009 for 6 countries and the rest of the world via multinational input-output analysis. Analysis results asserted that the existence of international trade caused the overall $\mathrm{CO}_{2}$ emissions in the global economy to decrease in comparison to the hypothetical situation without international trade. Another result of the study revealed that only China could not reduce $\mathrm{CO}_{2}$ emissions due to international trade and it was a pollution haven. Shao et al. (2019) examined the validity of PHH within the 1982-2014 data range in Brazil, Russia, India, China, and South Africa and MINT countries and found that $\mathrm{PHH}$ was not valid in both country groups.

\section{Data and Methodology}

In this part, the dataset utilized for the analysis is introduced. Furthermore, the methodology of the FKPSS unit root test developed by Becker et al. (2006) which allows sharp and smooth breaks is explained.

\subsection{Data}

This study aims to test the impacts of economic or political shocks to be applied to EF and its subcomponents in MINT countries within the data range of the 1961-2016 period are permanent or temporary. All data used for the analysis are obtained in per capita gha from the Global Footprint Network. Descriptive statistics for the dataset are shown in Table 1.

Figure 1 depicts the EF and its subcomponents in per capita gha for the selected countries over the period of 1961-2016. According to Figure 1, the largest share in the ecological footprints of all countries except Nigeria belongs to the carbon footprint.

\subsection{Methodology}

For the purpose of testing the stationarity of EF and its subcomponents, the FKPSS unit root test developed by Becker et al. (2006) is used in the study. The most important advantage of the Fourier KPSS test is that the locations, number and form of breaks in the series do not need to be predetermined. The main reason for Becker et al. (2006) extending the KPSS unit root test using the Fourier function is that the test can detect the movements of unknown functions. The FKPSS test can determine not only sharp changes but also smooth changes, and the location, number and shape of the structural changes do not influence the strength of the test. 
Table 1: Descriptive Statistics

\begin{tabular}{|c|c|c|c|c|c|c|c|c|c|}
\hline Country & & Mean & Median & St. Dev. & Country & & Mean & Median & St. Dev \\
\hline \multirow{7}{*}{ 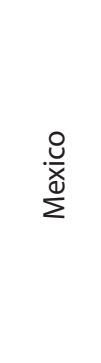 } & EF (Total) & 2.50 & 2.490 & 0.427 & \multirow{7}{*}{$\begin{array}{l}\frac{0}{0} \\
\stackrel{\mathscr{N}}{0} \\
\frac{0}{0} \\
\underline{\Xi}\end{array}$} & EF (Total) & 1.294 & 1.275 & 0.167 \\
\hline & Built-up land & 0.039 & 0.040 & 0.006 & & Built-up land & 0.044 & 0.050 & 0.014 \\
\hline & Carbon & 1.209 & 1.205 & 0.447 & & Carbon & 0.306 & 0.225 & 0.202 \\
\hline & Cropland & 0.518 & 0.515 & 0.082 & & Cropland & 0.354 & 0.365 & 0.074 \\
\hline & Fishing grounds & 0.056 & 0.065 & 0.022 & & Fishing grounds & 0.110 & 0.090 & 0.061 \\
\hline & Forest product & 0.268 & 0.260 & 0.022 & & Forest product & 0.459 & 0.415 & 0.249 \\
\hline & Grazing land & 0.404 & 0.370 & 0.116 & & Grazing land & 0.017 & 0.020 & 0.008 \\
\hline \multirow{7}{*}{$\frac{. \frac{\pi}{2}}{\stackrel{\frac{\pi}{2}}{Z}}$} & EF (Total) & 1.097 & 1.080 & 0.116 & \multirow{7}{*}{$\frac{\widehat{\vec{d}}}{\stackrel{\Xi}{\Xi}}$} & EF (Total) & 2.443 & 2.340 & 0.542 \\
\hline & Built-up land & 0.032 & 0.030 & 0.011 & & Built-up land & 0.027 & 0.030 & 0.007 \\
\hline & Carbon & 0.164 & 0.165 & 0.078 & & Carbon & 1.066 & 1 & 0.520 \\
\hline & Cropland & 0.482 & 0.485 & 0.096 & & Cropland & 0.899 & 0.890 & 0.070 \\
\hline & Fishing grounds & 0.056 & 0.050 & 0.016 & & Fishing grounds & 0.045 & 0.040 & 0.016 \\
\hline & Forest product & 0.271 & 0.275 & 0.046 & & Forest product & 0.241 & 0.240 & 0.048 \\
\hline & Grazing land & 0.089 & 0.090 & 0.026 & & Grazing land & 0.163 & 0.160 & 0.041 \\
\hline
\end{tabular}

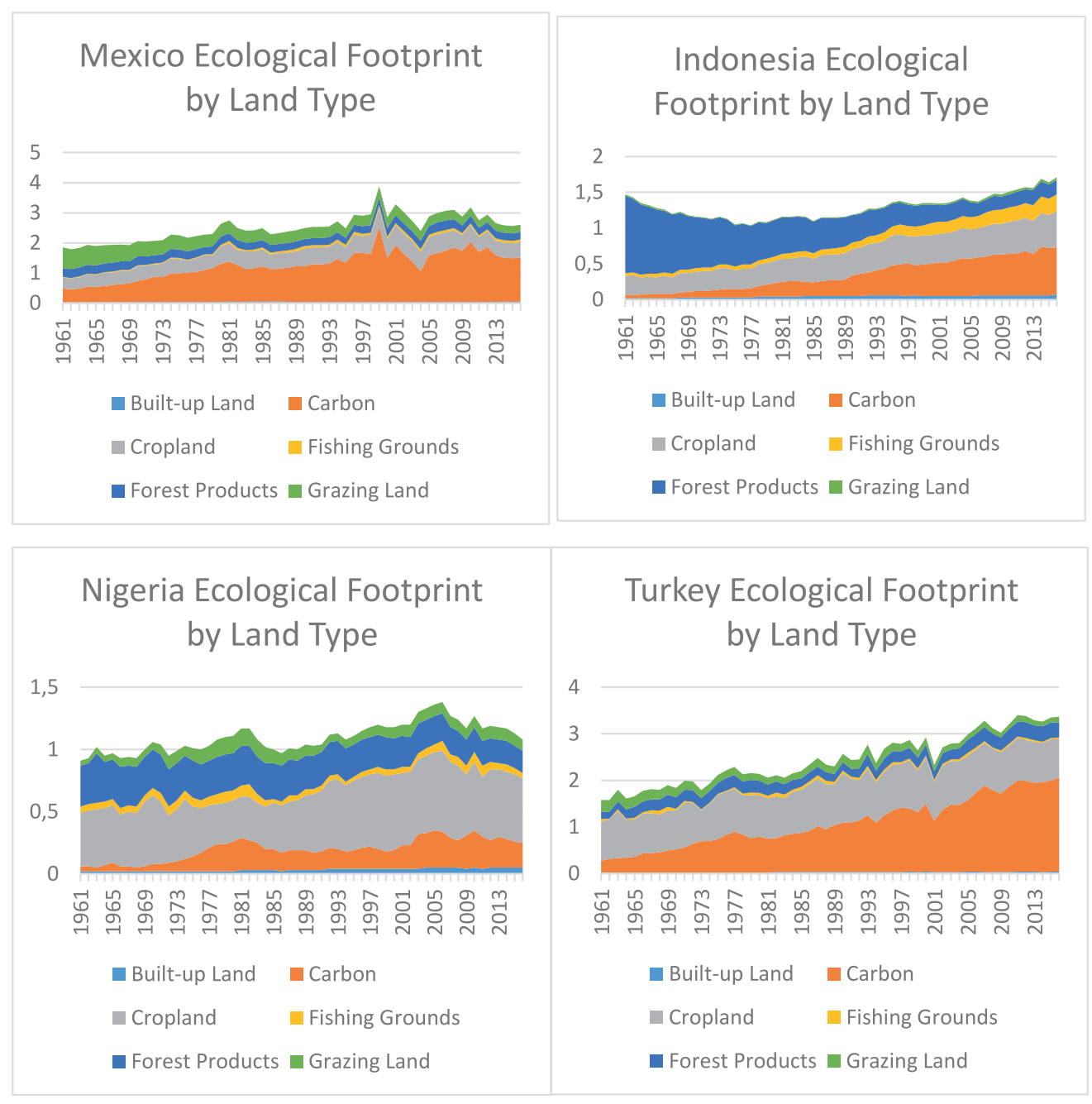

Figure 1: MINT countries' ecological footprints by land types 
Becker et al. (2006) considered the data creating process specified in Equations 2 and 3.

$$
\begin{aligned}
& y_{t}=X_{t}^{\prime} \beta+Z_{t}^{\prime} \gamma+r_{t}+\varepsilon_{t} \\
& r_{t}=r_{t-1}+u_{t}
\end{aligned}
$$

Here, $\varepsilon_{t}$ denotes the stationary error term, and $u_{t}$ denotes the error term that is independent and identically distributed with variance $\sigma_{u}^{2} \cdot Z_{t}=\left[\sin \left(\frac{2 \pi k t}{T}\right), \cos \left(\frac{2 \pi k t}{T}\right)\right]^{\prime}$. denotes the vector containing trigonometric terms such as, where represents the trend term, $T$ is the number of observations, and $k$ is the frequency value.

In order to calculate the test statistic required to test the stationarity null hypothesis $\left(H_{0}: \sigma_{u}^{2}=0\right)$, one of the Equations 4 or 5 is estimated and residues are obtained in the first stage.

$$
\begin{aligned}
& y_{t}=\alpha_{0}+\gamma_{1} \sin \left(\frac{2 \pi k t}{T}\right)+\gamma_{2} \cos \left(\frac{2 \pi k t}{T}\right)+e_{t} \\
& y_{t}=\alpha_{0}+\beta_{t}+\gamma_{1} \sin \left(\frac{2 \pi k t}{T}\right)+\gamma_{2} \cos \left(\frac{2 \pi k t}{T}\right)+e_{t}(5)
\end{aligned}
$$

Level stationarity null hypothesis is tested with Equation 4, while trend stationarity null hypothesis is tested with Equation 5. The test statistic is calculated with the help of Equation 6.

$$
\tau_{\mu}(k) \text { or } \tau_{\tau}(k)=\frac{1}{T^{2}} \frac{\sum_{t=1}^{T} \overline{S_{t}(k)^{2}}}{\overline{\sigma^{2}}}
$$

To determine the optimal frequency value, the value that gives the least sum of squares of residuals (SSR) is selected. If the data generation process does not contain a nonlinear trend, the standard KPSS stationarity test is stronger than the FKPSS stationarity test. Therefore, Becker et al. (2006) suggested testing the null hypothesis $\left(H_{0}: \gamma_{1}=\gamma_{2}=0\right)$ indicating the absence of nonlinear trend with the $F$ test statistic specified in Equation 7.

$$
F_{i}(k)=\frac{\left(S S R_{0}-S S R_{1}(k)\right) / 2}{S S R_{1}(k) /(T-q)}
$$

$S S R_{1}(\mathrm{k})$ denotes the SSR obtained from Equation 4 or Equation 5, $S S R_{0}$ denotes the SSR obtained from the regression in which the null hypothesis is valid, and $q$ is the number of independent variables. Critical values required for $\mathrm{F}$ statistics take place in Becker et al. (2006).

\section{Empirical Results}

The FKPSS unit root test results are shown in Table 2. The "frequency value" column in the table indicates the number of frequencies selected according to the minimum SSR value; significance of trigonometric terms are calculated by the " $F(k)$ "value, which indicates the F-test statistic value; whereas "FKPSS" indicates the test statistic value.

The null hypothesis of the FKPSS unit root test claims that the series is stationary, and the alternative hypothesis claims that the series contain unit root. If the FKPSS test statistic value is higher than the critical values determined by the number of frequencies, the null hypothesis will be rejected and the series will be determined to contain unit root.

According to the analysis results, cropland footprint in Mexico; cropland and grazing land footprint subcomponents in Nigeria; and fishing grounds and forest product footprint subcomponents in Turkey are detected as stationary at a $5 \%$ significance level. The F-test statistic should be checked in order to test the significance of the trigonometric terms of the variables which are detected as stationary at level. If the F-test statistic of stationary series is higher than the critical value, it will be determined that trigonometric terms are significant, otherwise, trigonometric terms are insignificant, therefore, the KPSS unit root test should be performed instead of the FKPSS unit root test. All the trigonometric terms of the variables (which are stationary) are detected to be significant at a $5 \%$ significance level.

According to the results of the analysis, the variables that were detected as stationary have mean-reverting tendency following a shock. As stated by Ozcan et al. (2019), technological evolutions that would reduce disruption can balance the impact of ecologic degradation. Moreover, policies aiming at reducing the level of pollution would be ineffective because of the temporary nature of policy shocks as well as the mean-reverting tendency of the series for cropland footprint in Mexico; cropland and grazing land footprint subcomponents in Nigeria; and fishing grounds and forest product footprint subcomponents in Turkey, which are detected as stationary as a result of the analysis. Moreover, since these variables are stationary, their future actions can be predicted by policymakers based on their past behaviors. Therefore, appropriate environmental policies can be designed for these stationary variables.

However, besides these variables, policymakers will not face any resistance if the size of other variables (such as built-up land footprint, carbon footprint, fishing ground footprint, forest product footprint, grazing land footprint subcomponents and total EF variables in Mexico; built-up land footprint, carbon footprint, cropland footprint, fishing ground footprint, forest product 
footprint, grazing land footprint subcomponents, and total EF in Indonesia; built-up land footprint, carbon footprint, fishing ground footprint, forest product footprint subcomponents, and total EF variable in Nigeria; and built-up land footprint, carbon footprint, cropland footprint, grazing land footprint subcomponents, and the total EF component in Turkey) are chosen to be changed since those variables are non-stationary at $5 \%$ significance level since the policy shocks will have permanent impacts on these variables in the long-run.

Consequently, the changes in EF and its subcomponents in each country over time are depicted in Figures A1-A4 in the Appendix. The blue lines in the figures illustrate the original timeline and the red lines illustrate the anticipated values. These lines indicate that both the sharp and smooth breaks from the figures are largely seized by the anticipated values within the timeline.

\section{Conclusion and Policy Implications}

The ecological footprint has been the main environmental indicator that is frequently examined in the relevant environmental economics literature, since it is not dependent on a single pollutant variable and is a composite indicator with many subcomponents. By not focusing on a single variable, it has allowed us to observe the effects of economic activities on the environment in a much more comprehensive way. The aim of this study is to examine the stationary properties of the ecological footprint and its subcomponents and to determine whether the effects of policies that will reduce the ecological footprint and increase environmental quality are permanent or temporary.

The findings obtained from the results of the stationarity analysis conducted on EF and its subcomponents in MINT countries via the FKPSS unit root test provide policymakers with valuable information. As a result of the study, it is determined that the vast majority of EF and its subcomponents are non-stationary at level and that the variables do not have mean-reverting tendency. Therefore, the impact of policy shocks is permanent.

Quite crucial is that the carbon footprint, which has the largest share in the total EF, is not stationary and that the policies implemented to reduce such a variable would have permanent impacts in all countries included in the analysis. Thus, technologies that would mitigate carbon emissions such as hybrid or electric vehicles and encouraging the use and improvement of these technologies would be effective in aggravating environmental quality. Furthermore, it has been determined that environmental taxes or environmental protection laws would be effective in reducing the carbon emissions of production units.

Table 2: FKPSS Test Results

\begin{tabular}{|c|c|c|c|c|c|c|c|c|c|}
\hline Country & & $\begin{array}{l}\text { Frequency } \\
\text { Value }\end{array}$ & $\mathrm{F}(\mathrm{k})$ & FKPSS $^{3}$ & Country & & $\begin{array}{l}\text { Frequency } \\
\text { Value }\end{array}$ & $\mathrm{F}(\mathrm{k})$ & FKPSS \\
\hline \multirow{7}{*}{$\frac{\stackrel{0}{u}}{\sum^{0}}$} & EF (Total) & 1 & 39.337 & 0.249 & \multirow{7}{*}{ 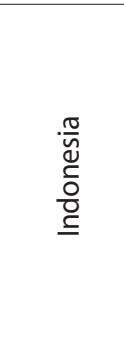 } & EF (Total) & 1 & 103.692 & 0.202 \\
\hline & Built-up land & 1 & 9.848 & 0.422 & & Built-up land & 1 & 37.439 & 0.412 \\
\hline & Carbon & 1 & 32.539 & 0.326 & & Carbon & 1 & 55.042 & 0.448 \\
\hline & Cropland & 1 & 46.622 & 0.160 & & Cropland & 1 & 45.809 & 0.428 \\
\hline & Fishing grounds & 1 & 65.272 & 0.455 & & Fishing grounds & 1 & 52.815 & 0.452 \\
\hline & Forest product & 1 & 14.209 & 0.216 & & Forest product & 1 & 33.153 & 0.434 \\
\hline & Grazing land & 1 & 18.446 & 0.439 & & Grazing land & 1 & 69.675 & 0.294 \\
\hline \multirow{7}{*}{$\begin{array}{l}\frac{0}{\frac{1}{d}} \\
\frac{0}{Z}\end{array}$} & EF (Total) & 1 & 30.612 & 0.193 & \multirow{7}{*}{ 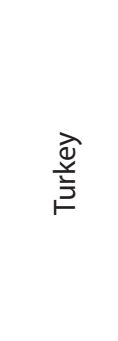 } & EF (Total) & 1 & 31.976 & 0.431 \\
\hline & Built-up land & 1 & 68.683 & 0.429 & & Built-up land & 1 & 28.506 & 0.443 \\
\hline & Carbon & 2 & 35.052 & 0.807 & & Carbon & 1 & 31.973 & 0.434 \\
\hline & Cropland & 1 & 78.876 & 0.069 & & Cropland & 1 & 11.423 & 0.214 \\
\hline & Fishing grounds & 2 & 25.968 & 0.482 & & Fishing grounds & 3 & 5.686 & 0.151 \\
\hline & Forest product & 1 & 24.675 & 0.430 & & Forest product & 2 & 8.051 & 0.358 \\
\hline & Grazing land & 2 & 41.879 & 0.205 & & Grazing land & 2 & 30.173 & 0.930 \\
\hline
\end{tabular}

${ }^{3}$ Critical values for frequency values 1,2 and 3 at $5 \%$ significance level are $0.1720,0.4152$, and 0.4480 , respectively. F test statistic is 4.929 at $5 \%$ significance level. 
Furthermore, fishing grounds and forest product subcomponents in countries except Turkey have been detected to be non-stationary at level. In these countries, water-polluting factors such as traditional agricultural activities, industrialization, and a high population growth rate can be reduced by focusing on green industries and supporting smart city systems.
Moreover, rapid urbanization and unplanned construction in these countries have resulted in the rapid destruction of forest areas. Measures need to be taken by determining city planning and prevention of illegal constructions in all countries except Turkey, which would also have permanent impact on forest product subcomponents. 


\section{References}

Ahmed, M., Khan, A. M., Bibi, S., \& Zakaria, M. (2017). Convergence of per capita $\mathrm{CO} 2$ emissions across the globe: Insights via wavelet analysis. Renewable and Sustainable Energy Reviews, 75, 86-97. doi:10.1016/j.rser.2016.10.053

Aldy, J. E. (2006). Per Capita Carbon Dioxide Emissions: Convergence or Divergence? Environmental \& Resource Economics, 33(4), 533-555. doi:10.1007/s10640-005-6160-x

Barros, C. P., Gil-Alana, L. A., \& Perez de Gracia, F. (2016). Stationarity and Long Range Dependence of Carbon Dioxide Emissions: Evidence for Disaggregated Data. Environmental and Resource Economics, 63(1), 45-56. doi:10.1007/ s10640-014-9835-3

Becker, R., Enders, W., \& Lee, J. (2006). A Stationarity Test in the Presence of an Unknown Number of Smooth Breaks. Journal of Time Series Analysis, 27(3), 381-409. doi:10.1111/ j.1467-9892.2006.00478.x

Bekhet, H. A., Othman, N. S., \& Yasmin, T. (2020). Interaction between Environmental Kuznet Curve and Urban Environment Transition Hypotheses in Malaysia. International Journal of Energy Economics and Policy, 10(1), 384-402. doi:10.32479/ijeep.8389

Cai, X., Che, X., Zhu, B., Zhao, J., \& Xie, R. (2018). Will developing countries become pollution havens for developed countries? An empirical investigation in the Belt and Road. Journal of Cleaner Production, 198, 624-632. doi:10.1016/j. jclepro.2018.06.291

Camarero, M., Picazo-Tadeo, A. J., \& Tamarit, C. (2013). Are the determinants of $\mathrm{CO} 2$ emissions converging among OECD countries? Economics Letters, 118(1), 159-162. doi:10.1016/j. econlet.2012.10.009

Chen, Q., \& Taylor, D. (2020). Economic development and pollution emissions in Singapore: Evidence in support of the Environmental Kuznets Curve hypothesis and its implications for regional sustainability. Journal of Cleaner Production, 243. doi:10.1016/j.jclepro.2019.118637

Christidou, M., Panagiotidis, T., \& Sharma, A. (2013). On the stationarity of per capita carbon dioxide emissions over a century. Economic Modelling, 33, 918-925. doi:10.1016/j. econmod.2013.05.024

Destek, M. A., \& Sarkodie, S. A. (2019). Investigation of environmental Kuznets curve for ecological footprint: The role of energy and financial development. Sci Total Environ, 650(Pt 2), 2483-2489. doi:10.1016/j.scitotenv.2018.10.017

Global Footprint Network. (2018). Global Footprint Network. Retrieved from https://www.footprintnetwork.org/ resources/data/

Hove, S., \& Tursoy, T. (2019). An investigation of the environmental Kuznets curve in emerging economies. Journal of Cleaner Production, 236. doi:10.1016/j.jclepro.2019.117628

Kapetanios, G., Shin, Y., \& Snell, A. (2003). Testing for a unit root in the nonlinear STAR framework Journal of Econometrics, 112.
Kruse, R. (2011). A new unit root test against ESTAR based on a class of modified statistics. Statistical Papers, 52(1), 71-85. doi:10.1007/s00362-009-0204-1

Kwiatkowski, D., Phillips, P. C., Schmidt, P., \& Shin, Y. (1992). Testing the null hypothesis of stationarity against the alternative of a unit root. Journal of econometrics, 54(1-3), 159-178.

Li, X.-L., Tang, D. P., \& Chang, T. (2014). CO2 emissions converge in the 50 U.S. states - Sequential panel selection method. Economic Modelling, 40, 320-333. doi:10.1016/j.econ$\bmod .2014 .04 .003$

Li, X., \& Lin, B. (2013). Global convergence in per capita CO2 emissions. Renewable and Sustainable Energy Reviews, 24, 357-363. doi:10.1016/j.rser.2013.03.048

López, L. A., Arce, G., Kronenberg, T., \& Rodrigues, J. F. D. (2018). Trade from resource-rich countries avoids the existence of a global pollution haven hypothesis. Journal of Cleaner Production, 175, 599-611. doi:10.1016/j.jclepro.2017.12.056

Munasinghe, M. (1992). Environmental Economics and Sustainable Development. Paper presented at the United Nations Conference on Environment and Development (UNCED), Rio de Janeiro, Brazil.

Narayan, P. K., \& Popp, S. (2010). A new unit root test with two structural breaks in level and slope at unknown time. Journal of Applied Statistics, 37(9), 1425-1438. doi:10.1080/02664760903039883

Ozcan, B., Ulucak, R., \& Dogan, E. (2019). Analyzing long-lasting effects of environmental policies: Evidence from low, middle and high-income economies. Sustainable Cities and Society, 44, 130-143.

Ozturk, I., Al-Mulali, U., \& Saboori, B. (2016). Investigating the environmental Kuznets curve hypothesis: the role of tourism and ecological footprint. Environ Sci Pollut Res Int, 23(2), 1916-1928. doi:10.1007/s11356-015-5447-x

Phillips, P. C., \& Sul, D. (2007). Transition modeling and econometric convergence tests. Econometrica, 75(6), 1771-1855.

Presno, M. J., Landajo, M., \& Fernández González, P. (2018). Stochastic convergence in per capita CO 2 emissions. An approach from nonlinear stationarity analysis. Energy Economics, 70, 563-581. doi:10.1016/j.eneco.2015.10.001

Rees, W. E. (1992). Ecological footprints and appropriated carrying capacity: what urban economics leaves out. Environment and Urbanization, 4(2), 121-130.

Shahbaz, M., Khraief, N., \& Hammoudeh, S. (2019). How Do Carbon Emissions Respond to Economic Shocks? Evidence from Low-Middle- and High-Income Countries. MPRA Paper, 93976.

Shao, Q., Wang, X., Zhou, Q., \& Balogh, L. (2019). Pollution haven hypothesis revisited: A comparison of the BRICS and MINT countries based on the VECM approach. Journal of Cleaner Production, 227, 724-738. doi:10.1016/j.jclepro.2019.04.206 
Solarin, S. A., Al-Mulali, U., Musah, I., \& Ozturk, I. (2017). Investigating the pollution haven hypothesis in Ghana: An empirical investigation. Energy, 124, 706-719. doi:10.1016/j. energy.2017.02.089

Solarin, S. A., \& Bello, M. O. (2018). Persistence of policy shocks to an environmental degradation index: the case of ecological footprint in 128 developed and developing countries. Ecological Indicators, 89, 35-44.

Solarin, S. A., Gil-Alana, L. A., \& Lafuente, C. (2019). Persistence in carbon footprint emissions: an overview of 92 countries. Carbon Management, 10(4), 405-415. doi:10.1080/1758300 4.2019.1620038

Stern, D. I. (2004). The Rise and Fall of the Environmental Kuznets Curve. World Development, 32(8), 1419-1439. doi:10.1016/j.worlddev.2004.03.004

Sun, C., Zhang, F., \& Xu, M. (2017). Investigation of pollution haven hypothesis for China: An ARDL approach with breakpoint unit root tests. Journal of Cleaner Production, 161, 153-164. doi:10.1016/j.jclepro.2017.05.119
Tisdell, C. A. (2010). Resource and environmental economics: modern issues and applications (Vol. 7). World Scientific Publishing Company.

Ulucak, R., \& Lin, D. (2017). Persistence of policy shocks to Ecological Footprint of the USA. Ecological Indicators, 80, 337-343. doi:10.1016/j.ecolind.2017.05.020

Wackernagel, M. (1994). Ecological Footprint and Appropriated Carrying Capacity: A Tool for Planning Toward Sustainability. (PhDThesis). The University of British Columbia,

Zambrano-Monserrate, M. A., Silva-Zambrano, C. A., Davalos-Penafiel, J. L., Zambrano-Monserrate, A., \& Ruano, M. A. (2018). Testing environmental Kuznets curve hypothesis in Peru: The role of renewable electricity, petroleum and dry natural gas. Renewable and Sustainable Energy Reviews, 82, 4170-4178. doi:10.1016/j.rser.2017.11.005 


\section{Appendix}

Mexico - Total ecological footprint

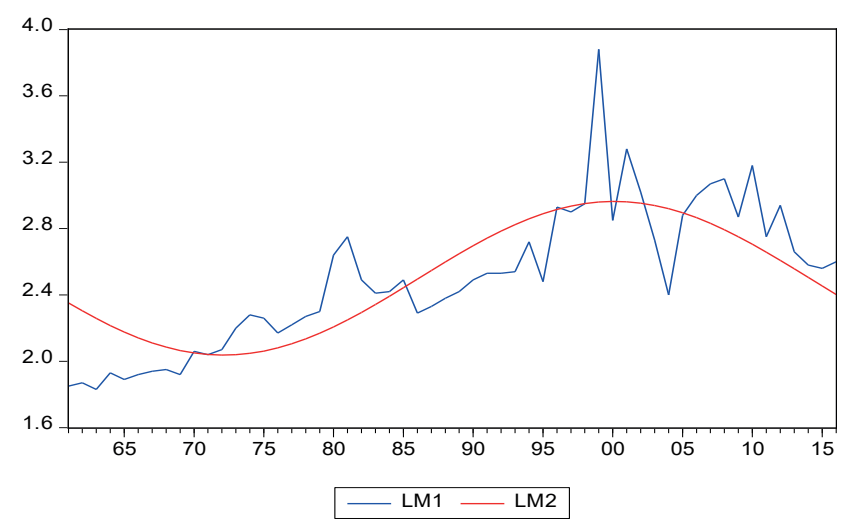

Mexico - Carbon

Mexico - Built up land
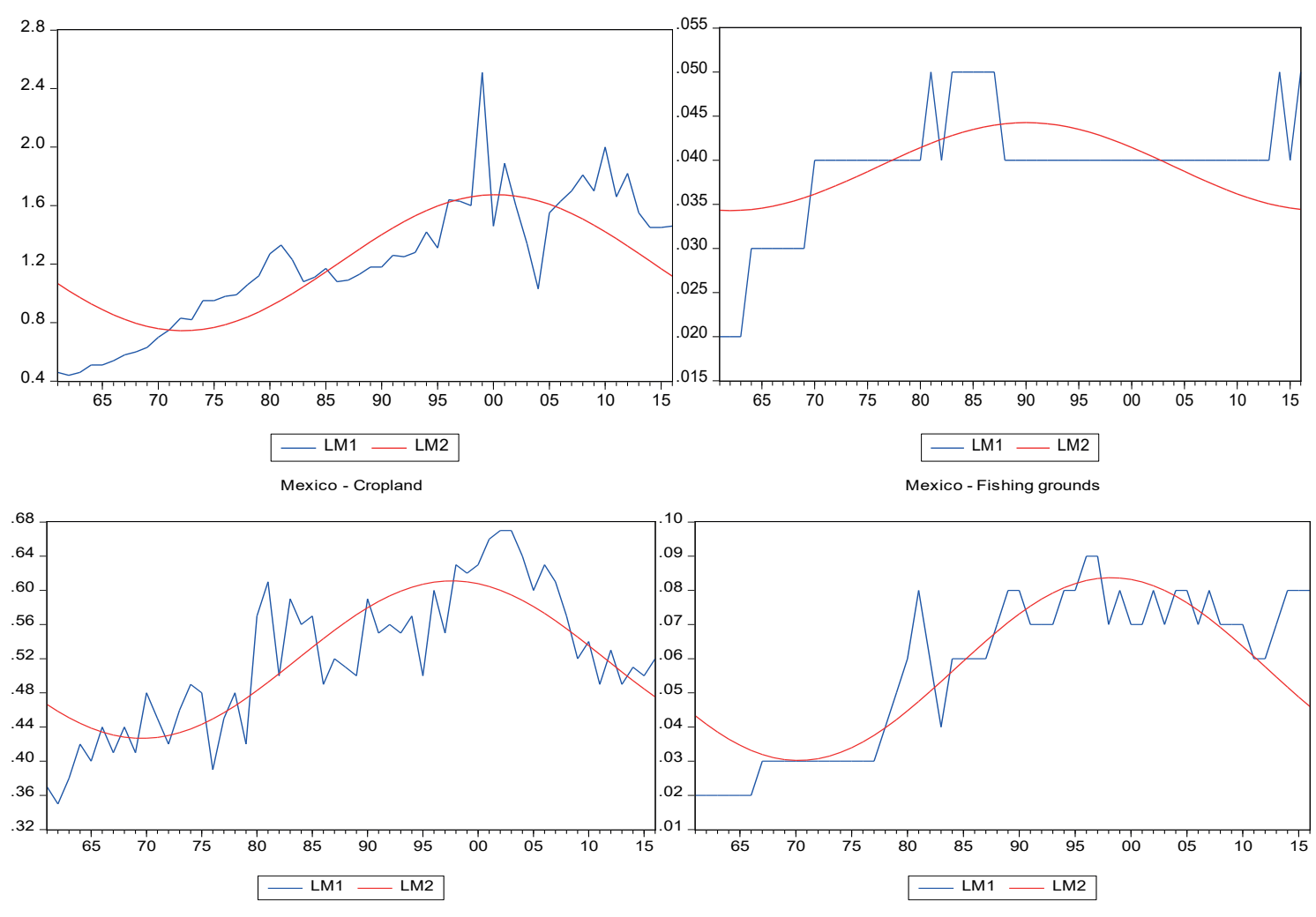

Mexico - Forest products

Mexico - Grazing land
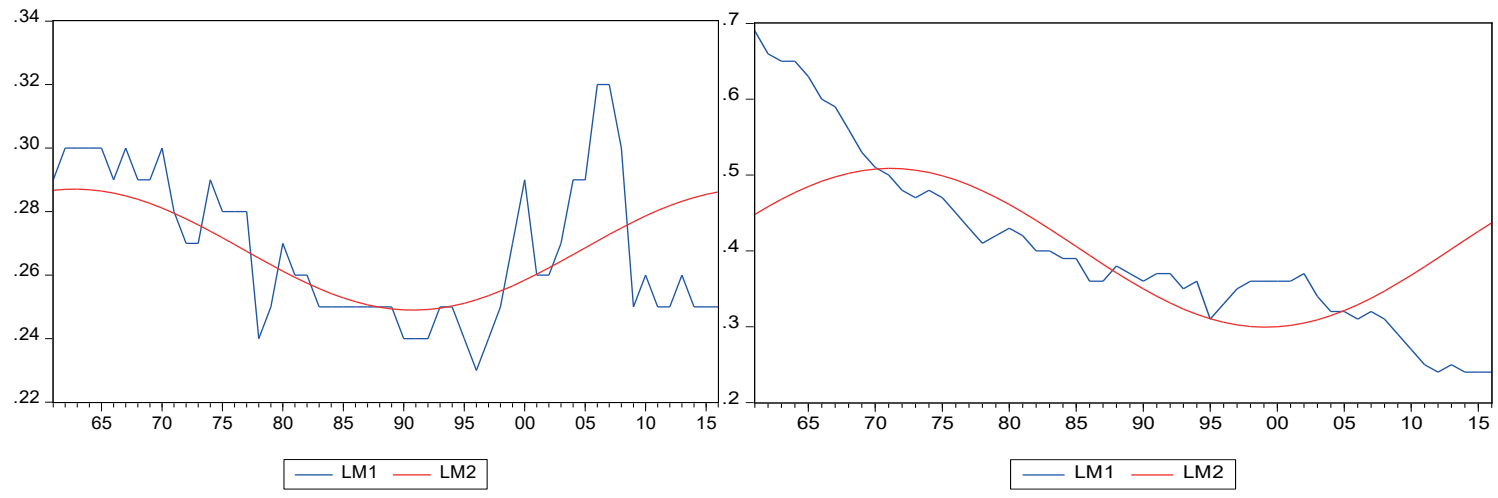

Fig. A. 1: Plots of ecological footprints and subcomponents in Mexico. 

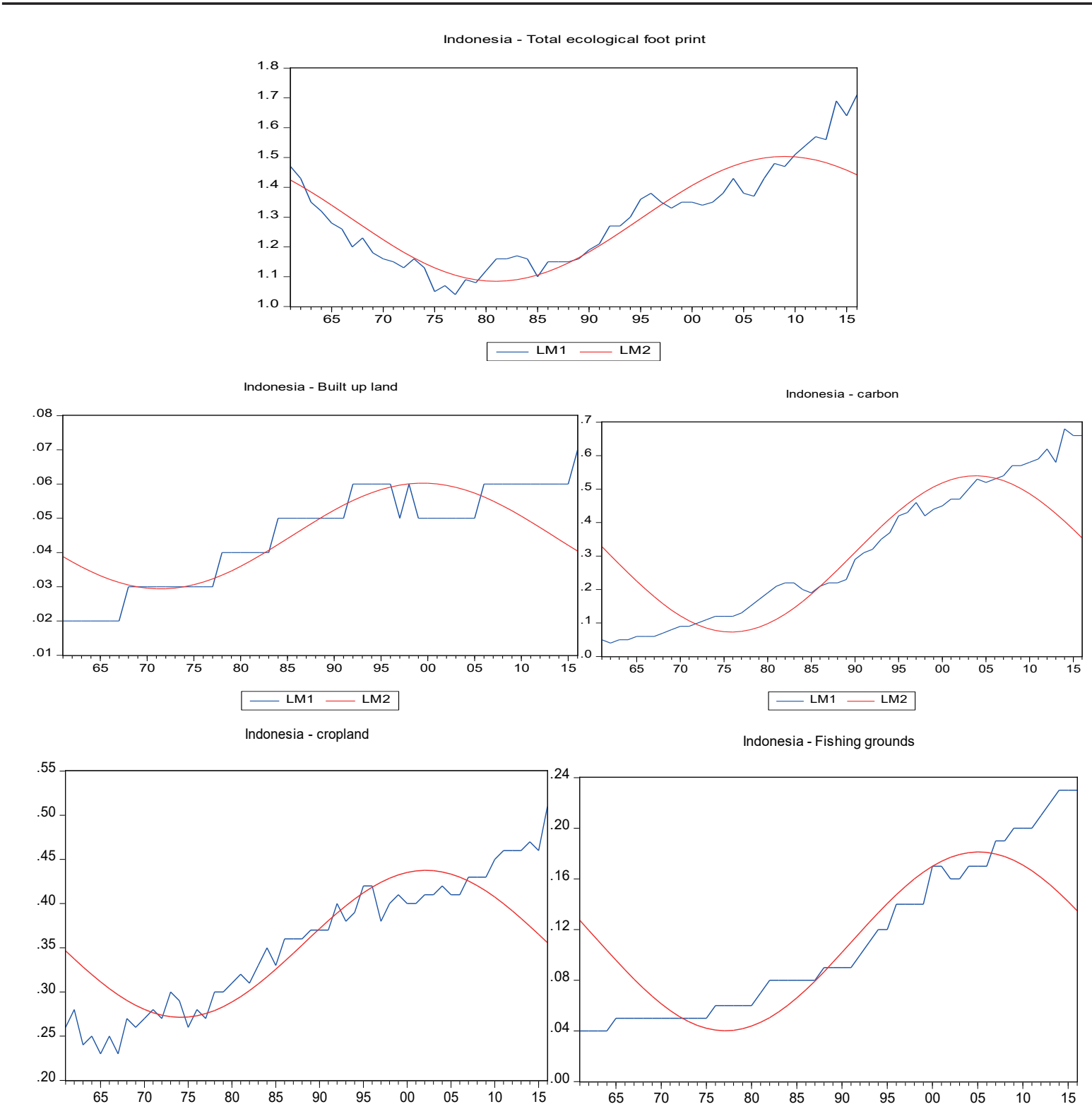

- LM1 LM2

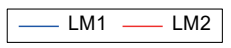

Indonesia - Forest products

Indonesia - Grazing land
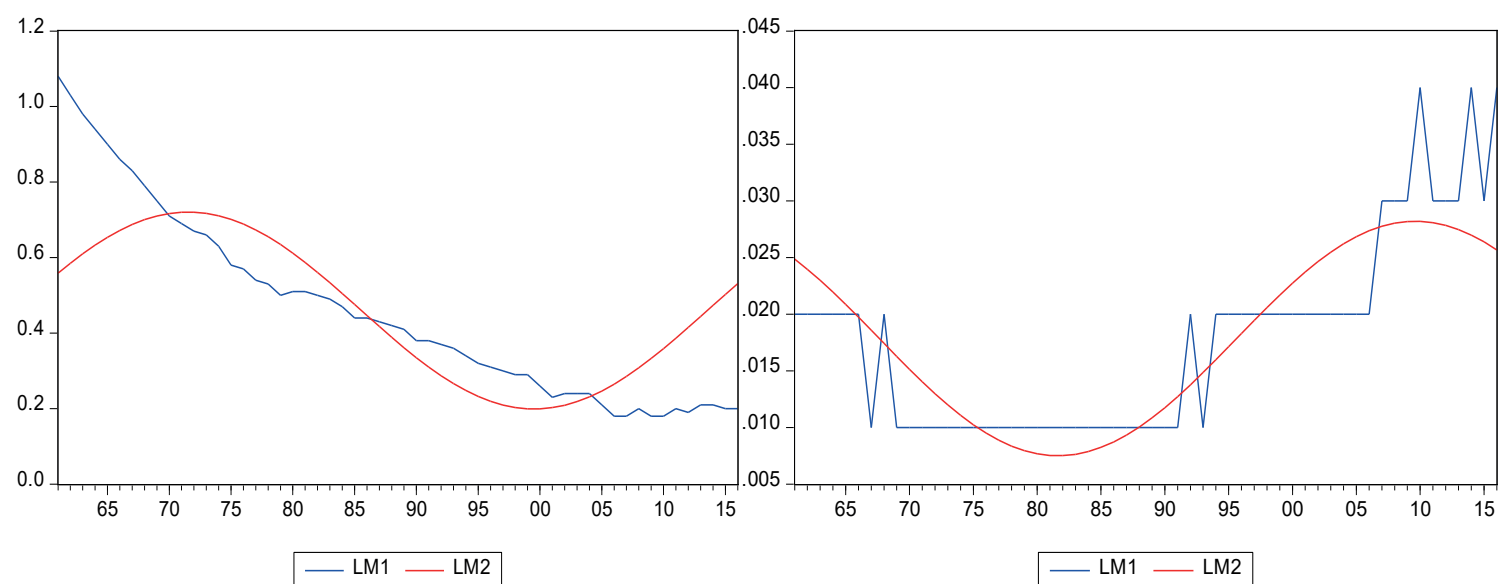

Fig. A. 2: Plots of ecological footprints and subcomponents in Indonesia. 
Nigeria - Total ecological footprint

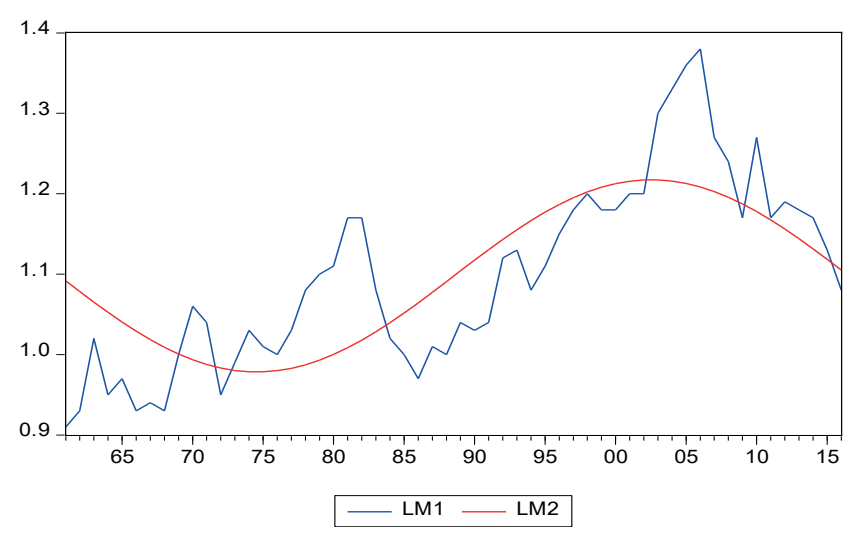

Nigeria - Carbon

Nigeria - Built up land
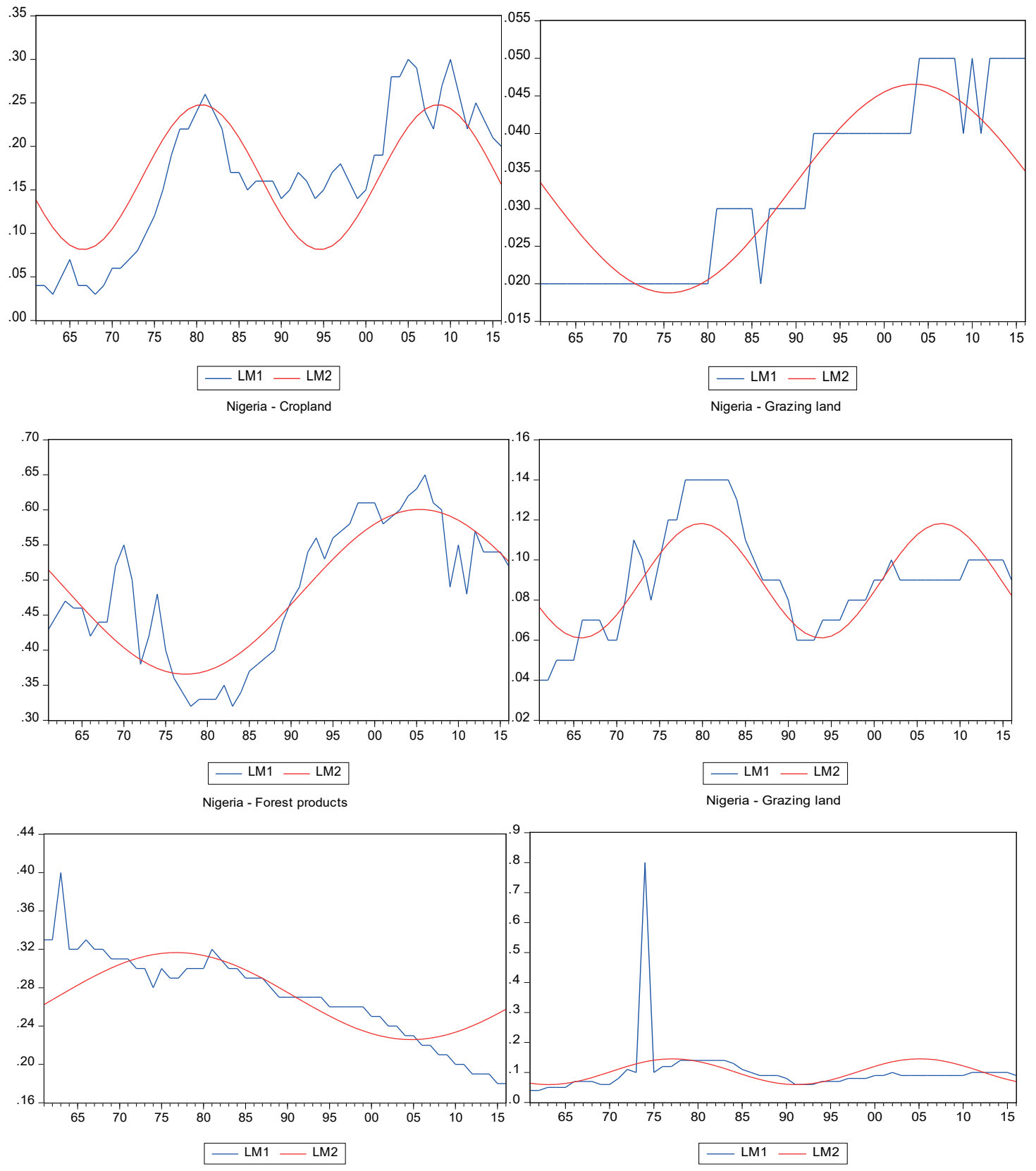

Fig. A. 3: Plots of ecological footprints and subcomponents in Nigeria. 

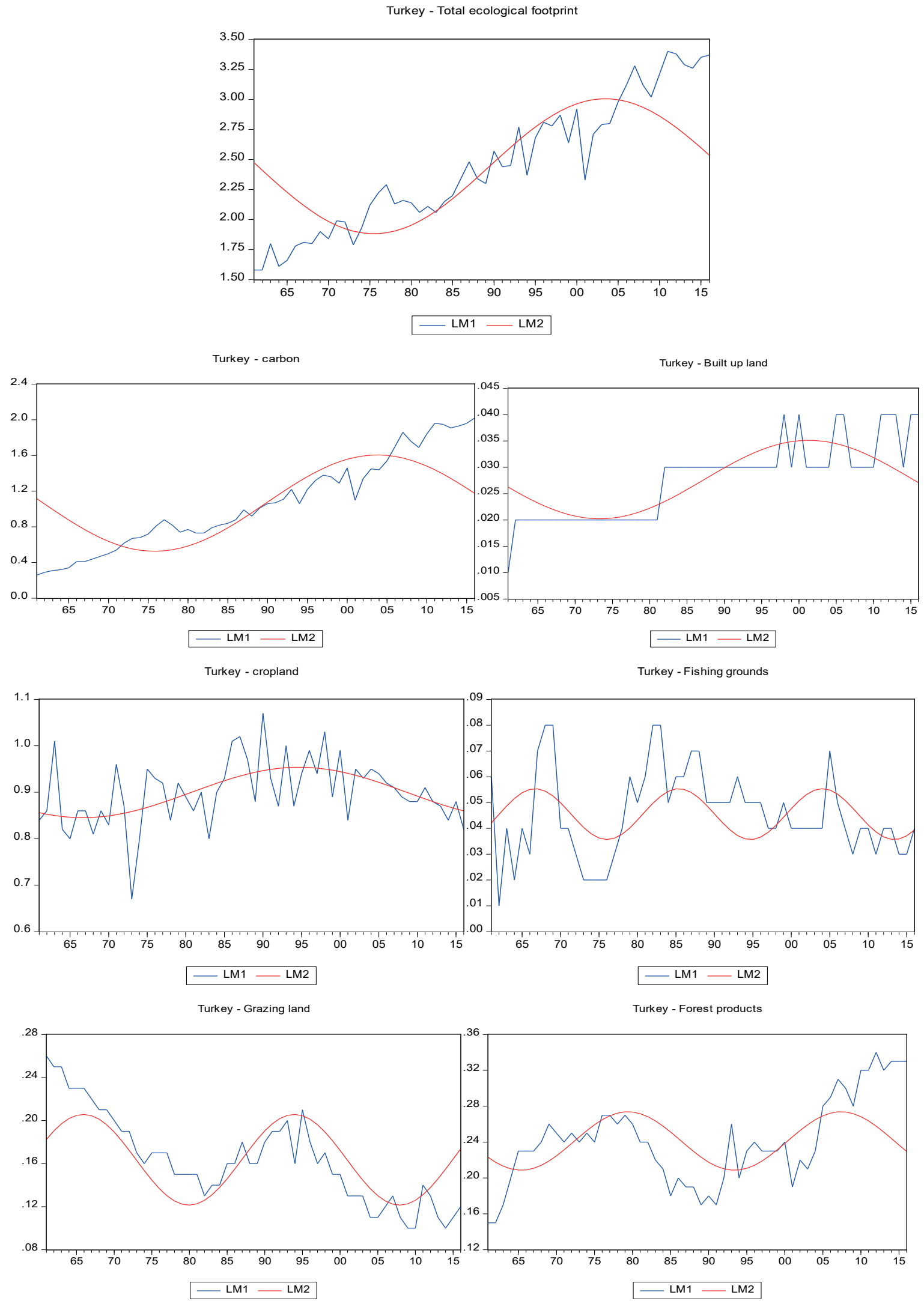

Fig. A. 4: Plots of ecological footprints and subcomponents in Turkey. 